appropriate for psychiatric conditions and a reduction in the associated stigma.

original papers

\section{Acknowledgements}

We are grateful for the advice and supervision provided by Professor Robin G. McCreadie, Crichton Royal Hospital, Dumfries. We would also like to thank Sister Olive Duncan of the Psychiatric out-patient department, Southern General Hospital, Glasgow and staff at the following Health Centres: Midlock Medical Centre, 7 Midlock St, Glasgow and Castle Douglas Health Centre, Academy St, Castle Douglas.

\section{References}

BROCKINGTON, I. F., HALL, P., LEVINGS, J., et al (1993) The community's tolerance of the mentally ill. British Journal of Psychiatry, 162, 93-99.
COWAN, I. \& HART, D. (1998) Changing Minds: every family in the land. A new challenge for the future. Psychiatric Bulletin, 22, 593-594.

JORM, A. F., KORTEN, A. E., JACOMB,

P. A., et al (1997) Helpfulness of interventions for mental disorders: beliefs of health professionals compared with the general public British Journal of Psychiatry, 171, 233-237.

LAWRIE, S. M. (1999) Attitudes of the general population to psychiatric and physicalillness. Psychiatric Bulletin, 23, 671-674
PRIEST, R. G., VIZE, C., ROBERTS, A., et al (1996) Lay people's attitudes to treatment of depression: results of opinion poll for Defeat Depression campaign just before its launch. $B M J$, 313, 858-859

THUMIN, F. J. \& ZEBELMAN, M. (1967) Psychology versus psychiatry: a study of public image. American Psychologist, 22, 282-286.

WOLFF, G., PATHARE, S., CRAIG,T., et al (1996) Public education for community care: a new approach. British Journal of Psychiatry, 168, 441-447.

\title{
The forgotten children: children admitted to a county asylum between 1854 and 1900
}

\section{AIMS AND METHOD}

To assess the part that the 19th century asylums played in the development of the discipline of child psychiatry. Admissions to the Worcester County Asylum between the years 1854 and 1900 were screened to identify children aged 16 and under. An item sheet was used to record details of the admission.

\section{RESULTS}

One-hundred and ninety-five children were admitted. Risk of suicide and dangerousness were routinely recorded, family history rarely. It was not possible to make retrospective diagnoses. The death rate was high and contact with the family was minimal post admission.

\section{CLINICAL IMPLICATIONS}

Children were treated exactly like the adult patients, and therefore asylums did not contribute significantly to the development of the discipline of child psychiatry.
The first attempt at a coordinated strategy for the provision of child and adolescent mental health services has been formulated only in the last decade of the 20th century (NHS \& Health Advisory Service, 1995). Until then the mental health of children had been the province of public and private agencies, whose policies were developed in the late 19th century and whose perspectives on children often still reflect this. Such a diversity of service origin is one of the strengths of mental health provision for children (Howells \& Osborn, 1980), but also a weakness in that it can lead to misunderstandings and confusion (Pearce, 1999).

The Lunatic Asylums Act 1845 made it mandatory for each borough and county to provide adequate asylum accommodation at public expense for its pauper lunatic population. Admissions to the asylum were a financial burden on the parish of origin, and therefore admission was a last resort (Tuke, 1898). There is a paucity of original source material, so little is known about the group of chil- dren who did get admitted. An examination of case notes of children admitted to Bethlem hospital is one of the few studies on this subject, but is not a representative view, as only people who had not been insane for over 12 months, or had never been discharged as insane from another hospital, were admitted there (Wilkins, 1987). I describe the children admitted to a typical county asylum between 1854 and 1900, using contemporaneous case notes.

\section{Method}

The Worcester County Asylum (Powick Asylum) in the village of Powick opened in 1854. Patient admissions were sequentially recorded in large leather-bound ledgers. Initially both males and females were recorded in the same book, but subsequently males and females were recorded separately. All ledgers available were examined and those children aged 16 and under on 
Table 1. Diagnostic categories used on admission notes

\begin{tabular}{lcc}
\hline Diagnosis & Age $4-10(n=34)^{*}$ & Age 11-16 $(n=161)^{*}$ \\
\hline Epilepsy & 22 & 64 \\
Idiocy & 20 & 34 \\
Mania & 3 & 60 \\
Dementia & 6 & 28 \\
Delusions & - & 4 \\
Moral imbecility & 1 & 1 \\
Melancholia & 1 & - \\
Imbecility & 3 & 18 \\
\hline
\end{tabular}

*70 children were given more than one diagnosis.

admission were identified. This age was taken as the cutoff to allow comparison with contemporary child and adolescent services. Dates of birth were never recorded in the case notes, only the patient's age in years.

The hospital ledgers relating to the years 18641867 and $1872-1876$ are missing.

The notes of all children and teenagers were then read and an item sheet was filled in. Any item not mentioned in the notes was deemed not to be present. No retrospective diagnoses were made.

\section{Results}

A total of 195 case notes were identified from a total of 6573 admissions to the Powick Asylum in the years 1854-1900. Two children aged 4 were the youngest to be admitted. Thirty-four were aged 10 or younger.

Four children admitted below the age of 10 were deemed to be suicidal and 10 of those under the age of 10 were deemed dangerous (29\%). Forty-two children over the age of 11 were deemed suicidal and 73 (45\%) dangerous to others. The diagnostic categories used on admission notes can be seen in Table 1.

It was not always noted from where the admission came. Three came from prison, three admissions were made from the workhouse in the under 10 age-group and 27 from those over the age of 11 .

A family history was only noted if it was positive (a close family relation was known to suffer from a mental disorder). Eleven children under the age of 10 (32\%) were noted to have a first- or second-degree relative with a mental disorder necessitating admission, were deemed idiotic or feeble minded, or had parents noted to drink excessively. Thirty-one children over the age of 11 had a positive family history.

\section{Aetiology}

Most conditions were deemed to be hereditary or cause unknown. Some of the other explanations for admission are given in Table 2 .

Treatment was recorded only rarely. The range of treatment was bromide, chloroform, blisters, brandy, ammonia, digitalis and eggs (given on two occasions to private class patients)
Table 2. Explanation given for the cause of some admissions

\begin{tabular}{|rr} 
& $n$ \\
\hline Mania & 63 \\
Sunstroke & 1 \\
Measles & 1 \\
By being thrown from a trap & 1 \\
Fright and uterine derangement & 1 \\
Loss of employment & 1 \\
Abdominal tumour & 1 \\
Fright by a dog & 1 \\
Over study & 1 \\
Non-appearance of menses & 1 \\
Uterine functional derangement & 1 \\
Frightened by a cow & 1 \\
Epilepsy & 86 \\
By being put inside a recently killed pig & 1 \\
Scarlet fever & 1 \\
Worms & 1 \\
Fright of mother during pregnancy & 2 \\
Tossed by a cow & 1 \\
Imbecility & 1 \\
Cutting teeth & 1 \\
Eright at being almost drowned & 1 \\
\hline
\end{tabular}

original

papers
Of the 34 children admitted who were aged between 4 and 10, five were discharged cured, 11 were transferred to a long-stay ward and four were transferred to another hospital. There were 11 deaths and three outcomes were unrecorded.

There were 161 children between 11 and 16, of whom 47 were discharged cured. Fifty-eight were transferred (41 to a long-stay ward; 17 to another hospital) and there were 38 deaths. Eighteen children had unrecorded outcomes.

\section{Discussion}

During the 19th century the attention paid to the mental health of children was influenced by the physical health of the population, the cultural climate of the day and beliefs about children and child rearing (Von Gotard, 1988). The fact that children were admitted to an asylum for years and frequently died there without apparent contact with their family must be set in the context of a high infant mortality (156 per 1000 live births in 1897) and difficulties in travel and communication among pauper families. Although there is virtually no recorded contact with families of origin once admitted, not all families abandoned their children. One child was nine years old when admitted in 1878, suffering from 'congenital idiocy'. Six months after admission the notes state

"Parents have been extremely anxious to have him home and have written one or two very unpleasant letters. He was discharged at fathers request."

Despite the high death-rate in the community, the death-rate for children entering the asylum seems abnormally high. A child had a one in five chance of dying before 
the age of 5 during this period (Lane, 2001), but if admitted, the odds shortened to one in three. The high death-rate, of almost one in four, is particularly striking in the 11-16 year

original papers

olds, who would not normally have been at great risk once the vulnerable period of early childhood was past. There may be several reasons for this. Fourteen per cent of the children were from the workhouse. These children may have already been weakened by their poor environmental conditions and, therefore, were susceptible to disease spread by contagion, e.g. tuberculosis. Some of the behavioural manifestations of their illnesses were likely to be organic in origin, and admission to an asylum made erroneously.

It is highly unlikely that asylums provided a sympathetic environment for children. Children were treated in exactly the same way as adults, with the difference that boys were kept on the female wards until they were about 7 or 8 years old. Admission procedures were identical for adults and children. The method of assessment of dangerousness is not detailed, but children as young as 4 were identified as dangerous and this is recorded in the same way as for adults.

The nature of the confinement meant that abuse was a possibility. An 11-year-old boy "was caught in another patient's bed and was moved into another dormitory. A small blister was applied to his penis and at the side of his anus".

It is not possible to equate the diagnoses of the day with recognisable contemporary diagnoses. The very high prevalence of epilepsy (Table 1) may be a real finding, indicating the high level of organic disease causing behavioural problems, or may be a misdiagnosis. Idiocy was found to be a common diagnosis for those under the age of 10 , but does not necessarily indicate cognitive deficits. Idiocy was a term given to less dangerous inmates, whose cost on the public purse was less because they could contribute to the functioning of the hospital by doing jobs such as gardening or working on the farm. Some of the children diagnosed as idiots could read and write, and were thus discharged cured. The general view was that idiocy was an example of reversion to a lower type in the evolutionary scale. Another reason for diagnosing most children as idiots was the prevailing belief that insanity only occurred in those who could lose their reason. Children were considered to be born without reason, which gradually grew in them as they developed to adulthood. They could not then, by definition, be insane.

As puberty was reached mania became the prevalent diagnosis, attributed to various causes. This can provide interesting insights about beliefs of the time. A 14-year-old girl was admitted in 1869 with acute mania:

"Her father states that while working in the fields she was accosted by a woman who has the reputation of performing witchcraft, who told her that her throat would be cut".

She was discharged in May 1870 recovered.

While many of the points raised above could easily lead to the belief that the asylum was a dreadful fate for children, in one or two cases it may have provided a better environment than the community from which they came. A female domestic servant, aged 16 , was admitted with a 3-week history of acute mania which was "said to be due to ill-treatment by the stepfather. She is staying out at night and drinking. She sees men in the room and hears voices. She feels impelled to kill someone, especially children . . looks as if she has been on short commons".

\section{Conclusions}

Children admitted to the asylum in the 19th century were admitted for much the same reasons as children are admitted to psychiatric wards today: they were unmanageable in the community or in the institutions from which they were referred. Although it is not easy to apply current diagnostic systems to the presenting problems, there is enough detail to suggest that behaviour difficulties were the precipitating cause for admission, whatever the underlying psychopathology.

Social historians (Foucault, 1965; Scull, 1979) have stated that changing society, increased industrialisation and declining community tolerance for the mad forced the insane into asylums, allowing the psychiatrists of the day to assume an expertise and carve out a speciality for themselves. A sub-speciality of child psychiatry did not evolve within this context. This was possible owing to the overarching influence of Maudsley, who believed children to be 'brute' beings governed by the animal passions rather than by reason (Wardle, 1991). Modern child psychiatric services have evolved from different roots to these. Society is, however, changing rapidly, and many child mental health specialists find themselves being forced to adopt society's agendas for 'disturbed' children. It is perhaps salutory to study the history of psychiatry before specialist child services existed, and to move on.

\section{References}

FOUCALT, M. (1965) Madness and Civilization: A History of Insanity in the Age of Reason. NewYork: Pantheon.

HOWELLS, J. G. \& OSBORN, M. L. (1980/ 81) The history of child psychiatry in the United Kingdom. Acta Paedopsychiatrica, 46, 193-202.

LANE, J. (2001) A Social History of Medicine, Health, Healing and Disease in England, 1750-1950. London \& New York: Routledge.

NATIONAL HEALTH SERVICE \& HEALTH ADVISORY SERVICE (1995) Child and

Adolescent Mental Health Services: TogetherWe Stand. The Commissioning Role and Management of Child and Adolescent Mental Health Service. London: HMSO.

PEARCE, J. B. (1999) Collaboration between the NHS and social services in the provision of child and adolescent mental health services: a personal view. Child Psychology and Psychiatry Review, 4, No 4.

SCULL, A. (1979) Museums of Madness, the Social Organisation of Insanity in Nineteenth Century England. London: Allen Lane.

TUKE, J. B. (1998) Address to Annual Meeting of British Medical Association. Lancet, 6, 313-314.

VONGOTARD, A. (1988) The development of child psychiatryin 19thcentury Britain. Journal of Child Psychology and Psychiatry, 29, 569-588.

WARDLE, C. J. (1991) Historical influences on services for children and adolescents before 1900. In 150 years of British Psychiatry 1841-1991 (eds G. G. Berrias \& H. Freeman), pp. 279-293. London: Gaskell.

WILKINS, R. (1987) Hallucinations in children and teenagers admitted to Bethlem Royal Hospitalinthenineteenth century and their possible relevance to the incidence of schizophrenia. Journal of Child Psychology and Psychiatry, 28 $569-580$.

Kate Gingell Consultant Child and Adolescent Psychiatrist, Dudley Priority Health NHS Trust, The Elms Health Centre, Slade Road, Cradley, West Midlands B63 2UR 